\title{
ScIDioc
}

International Journal of Finance, Economics and Trade (IJFET) ISSN 2643-038X

\section{Scrutiny of E-Mail Discourse Features in an Organization Using Speech Act Theory}

Mitra Madanchian ${ }^{1 *}$, Hamed Taherdoost ${ }^{2}$

${ }^{1}$ Research Club (Research \& Development Departement), Hamta Group, Hamta Business Corporation, Vancouver, Canada.

${ }^{2}$ University Canada West, Vancouver, Canada.

\section{Abstract}

Nowadays, most business communications and transactions are conducted via Computer Mediated Communication (CMC) and as email is the most familiar type of CMC. In reality email communication plays a vital role in establishing and maintaining business relationships, both within a company and with external contacts. This study investigates features of email discourse in workplace communication. Email exchanges are analyzed in order to clarify how members of an organization interact with each other using emails to achieve specific communicative needs of the organization. The data of this study consist of a corpus of email messages $(\mathrm{N}=112)$ which are exchanged among members of a selected Iranian organization and collected over a stipulated period.This study drew on the Speech Act Theory framework as the basis for analyzing and explaining the qualitative data. In addition, data was analysed using Nvivo. Finally, the study concludes that the employees in this Iranian organization adopted a variety of discourse and rhetorical strategies to achieve the specific communicative needs at the workplace. The selected strategies reflect the writer's interpersonal relationship with their email intractants. Finally, the findings clarified the features of email discourse.

Keywords: Computer-Mediated Communication (CMC); E-mail Discourse; Organization; Speech Act Theory; Nvivo.

\section{Introduction}

Nowadays, information technology performs an enormously important position in various corporations and organizations, and therefore electronic mail is hired drastically as a technique of Computer-Mediated Communication (CMC). Several sorts of $\mathrm{CMC}$ have a massive impact on corporations at the insight of the fact that they may be short, quick and straightforward [1,2]. This study makes a specialty of e-mail communication within an organization and explores e-mail communication and its associated utilization in a specific Iranian production corporation.

The majority of corporate interactions and transactions are now performed through CMC, with email being the most widely used type of CMC. It has evolved into a formidable force in modern communication. In fact, email is critical for developing and sustaining business ties, both within and outside of a firm [2]. E-mail has supplanted conventional forms of communication such as phone calls, letters and faxes, and has become a standard mode of contact in all corporate settings [1].
Emails are crucial in many organizational processes such as information exchange, project management, and client support. The email networks are becoming very popular for both analysis and visualization [2]. Electronic communication such as emails and instant messages among employees are usually archived in the organizations and these can be used to identify the informal communication structure within the organization apart from discovering common interests among individuals [2], which can help the organization to achieve effective communication.

Email communications are more ambiguous and can be easily misunderstood than is commonly understood $[3,4]$. A combination of distinctive written and spoken factors in email results in messages that are far more natural, minor distance and formal, when compared with traditional composed communication [5-7]. These particular characteristics provide a number of intriguing questions about email in general (e.g. what is the weakness and strength of email use?) and using email as the primary means of communication in particular the business setting.

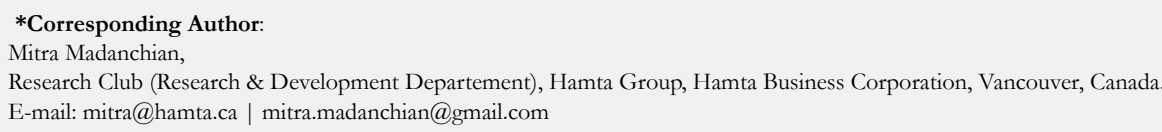

Copyright: Mitra Madanchian 2021. This is an open-access article distributed under the terms of the Creative Commons Attribution License, which permits unrestricted use, distribution and reproduction in any medium, provided the original author and source are credited. 
The literature reveals that most of the studies concerning email communication and discourse in Iran have been mostly carried out within the education context and not within the business context. This therefore highlights that there is indeed a lack of knowledge of the features and characteristics of email discourse in the Iranian businesses and thus creates a gap in the understanding of how emails are used in Iranian organizations within the business context [8]. Therefore, an investigation on how emails are used in Iranian business context may provide insights into the Iranian ways of communication via emails and hence contribute to a body of knowledge about CMC in the Iranian context.

This study has provided an insight into Iranian business' email as a kind of discourse. The findings are useful to create materials about features of email communication in the Iranian business context which can be incorporated into English for Specific Purposes (ESP) teaching and training and how email messages could indicate the features of both spoken and written communication in comparison to the traditional medium of communication that utilizes traditional writing convention.

\section{Theoretical Framework}

The settings wherein texts are generated by participants of an enterprise ought to be understood in an effort to observe the speech of that enterprise. This is due to the fact that the textual content's meaning is formed by its surroundings. As a result, comprehending a textual content necessitates looking the discourse that consists of the context in addition to the folks who created that context [9].

The concept of speech act matches the criteria since the research investigated the meaning ascribed to texts generated by members of the organization in the course of their regular activities. Because this is a pragmatic theory-based discourse analysis, the speech act theory was used to categorize and analyze the emails in order to explain what individuals are doing in their email conversations. This is due to the fact that the theory explains utterances in terms of the language's functions. The Speech Act Theory [10], which is linked to communicational needs modeling, is used in this study to support the pragmatic viewpoint since it defines how individuals within an organization use language to communicate and how they use language across various communities [11].

\section{Speech Act Theory}

Speech acts are the fundamental building blocks of linguistic communication [10]. Austin [12] developed speech act theory in his book How to Do Things with Words. Speaking, according to Austin, is a sort of action, which is further specifically defined by Searle [10] as "[a] in linguistic communication involves linguistic acts". As a result, a theory of speech acts is a subset of an action theory.

Austin divides the entire speech act into three specific phasesAustin [12]: locutionary act, illocutionary act and perlocutionary act. A locutionary act is the deliberate production of sounds guided by rules of grammar and pronunciation in order to express something. The act of expressing anything, such as requesting or promising, is referred to as an illocutionary act. The major result of the hearer's execution of the illocutionary act is referred to as a perlocutionary act. The speaker can really conduct three acts at once by saying; the bar will be closed in five minutes.

When the noises of the bar closing in five minutes are stated, it is considered a locutionary act. The speaker performs an illocutionary act by informing the audience that the bar will close in five minutes and maybe advising the crowd to order one final drink. Because the crowd assumes the bar will close shortly, they order the last drink, resulting in a perlocutionary act. Illocutionary acts are of primary concern to pragmatists, and the word speech act is frequently used to refer to an illocutionary act. When a complete illocutionary act is executed, three separate actions occur simultaneously, according to Searle [10]: an utterance act, a propositional act, and an illocutionary act. An illocutionary act is coupled with a propositional act. As a result, a propositional act is a component of an entire illocutionary act. Searle [10]: The illocutionary power indicator and the propositional indicator. The preceding indicates the sort of speech act, whereas the conclusion indicates the propositional act. Word order, verb mood, explicit performative verbs, stress, intonation, grammar and punctuation, and other factors contribute to illocutionary power indicators.

The propositional indicators are often expressed by that which comes before the embedded clauses, as in I promise that I will arrive, where the term "I promise" is the illocutionary force indication of promising and the highlighted portion is the indicator of propositional content. The utterance I promise to arrive, which is equal to I promise that I shall come, has the propositional content indication. [10]. Directives, representatives, commissives, declaratives, and expressive utterances are among the roles identified by Searle [10]. According to Coulthard [13] claims that, Searle proposed the five functions as macro-classes of illocutionary act, by the same names.

\section{Directives}

A directive can be expressed by a speaker's request to be followed by a listener. The speaker is attempting to persuade the listener to take action. Coulthard [13] explains that "the speaker is WANTING to achieve a future situation in which the world will match his world and thus this class includes not simply 'order' and 'request' but more subtly 'invite', 'dare' and 'challenge'. The directing function can be expressed in two ways: the imperative and the polite imperative. However, natural speakers of a language might employ a variety of structures to accomplish the same goal.ErvinTripp [14] cited in Hatch [15], as indicated in Table 1, divided directions into five categories.

The sensitivity to social groupings is another aspect that impacts our decision on directive forms. This is highlighted by Hatch [15] who states that, "all languages have directive but the variation in directive forms within a language must be sensitive to social constraints".

\section{Commissives}

Commissives are comments that are intended to be taken as promises or denials of action. Commissives, according to Coulthard [13], are similar to directions, but the aim is to get the speaker to act, thus commissives primarily entail purpose. Commissives vary in strength, thus they can be extremely powerful or extremely 
Table 1. Types of directives classified by Ervin-Tripp (1972).

\begin{tabular}{|c|c|c|}
\hline Type of directives & Address & Example \\
\hline $\begin{array}{c}\text { Personal need/desire } \\
\text { statements }\end{array}$ & Subordinates & I need/want X \\
\hline Imperative & Subordinate or familiar equals & Give me X \\
\hline Imbedded imperative & $\begin{array}{c}\text { Unfamiliar people, people who differ in rank or who are } \\
\text { physically distant; someone who is in his or her own territo- } \\
\text { ry, someone whose willingness to comply is in doubt }\end{array}$ & Could you give me X \\
\cline { 3 - 4 } & $\begin{array}{c}\text { Someone who might not comply; also used when there is an } \\
\text { obstacle to compliance }\end{array}$ & $\begin{array}{c}\text { May I have X? Is there any X } \\
\text { left? Do you have X? }\end{array}$ \\
\hline Permission directive & $\begin{array}{c}\text { Persons with sheared rules such as members of a family, } \\
\text { people living together, and work groups. }\end{array}$ & $\begin{array}{c}\text { This has to be done over, } \\
\text { what about the X? }\end{array}$ \\
\hline Hint (sometimes with \\
humour)
\end{tabular}

avoided in any positive or negative direction. In Hatch [15] two instances are given: 1) probably I can do tomorrow. 2) Don't get concerned, I'll be there. The forms employed for commissives, like directions, vary depending on social connections or work ritual limitations. Across linguistic and cultural groups, the appropriateness of commissives and directions vary. As a result, it's a promising topic for future cross-cultural communication study.

\section{Representative}

A representative speech act is one that may be evaluated for its accuracy. The goal is to 'commit the speaker to anything being the case,' which implies that it is an utterance in which the speaker applies his words to the reality, which includes his 'BELIEF that $\mathrm{p}^{\prime}$ [13]. The truth value of a statement might change depending on how hedged or motivated it is. Lexical hedges can be used to attenuate the statements stated. "Approximately," "very," "nearly," and "extremely" are examples of lexical words that serve as hedges, weakening or strengthening claims. As a result, hedges are employed to qualify, soften, or politing assertions. They also have a ceremonial role, similar to disinfluencies, in that they smooth over disagreements with conversational partners [15].

\section{Declaratives}

Declaratives are speech acts that, once pronounced, result in a new condition of being, which Austin [12] attributes to as per formatives.. A few examples were given by Hatch [15] include the following: (a) if a judge declares "I find you guilty as charged," (b) When pupils stand up and depart, there is a change. However, the utterance "I declare these truths to be self-evident..." It is not declarative if everyone already believed the truths to be selfevident before procumbent, because no actual change occurs as a result of the utterance. In conclusion, the person who makes a declaration must have the authority derived from their job or status to do so.

\section{Expressive}

Expressives are words that express our delight, disappointment, preferences, and dislikes. There is no dynamic link between words and the reality, according to Coulthard [13] and no fundamental psychological verb. He states that 'the point of this class is to express the psychological state specified in the sincerity condition about a state of affairs specified in the propositional content'. The examples given are 'thank', 'apologize', and 'deplore'. From indirect to direct, or from hedging to exacerbated expressions, the expressive can be ordered along a strength continuum. The expressive range is mediated by social variables, which are societal ritual limitations. Furthermore, the shape of expressive and expectations for when expressive is appropriate varies among linguistic groups, as do the form and strength of expressive.

\section{Research Methodology}

The previous sections outlined the theoretical framework for this study. This section describes an empirical research project that was designed to determine the features of email discourse in organization. The research questions for this study are:

Q1. What are the functions of the transmitted messages in Iranian email discourse?

Q2. What rhetorical strategies are used in the different type of message?

For this study, the instrument used is a checklist framework for the selection of email messages adopted from H. [9], and the Nvivo 8 software to analyze the email messages. The checklist for the selection of email messages included a list of criteria to identify the emails to be selected was adopted from [9]. These included email messages sent and received by members of the organisation. The researcher used this checklist to give an insight to the readers to show how the researcher selected email messages from the data. The emails were both one-way and chain emails, written in English, sent to single or multiple recipients. The checklist provided was as follows:

Criteria for the selection of email messages [9]:
$\checkmark$ Work-related
$\checkmark$ One-way email
$\checkmark$ Chain of emails
$\checkmark$ Single or multiple recipients
$\checkmark$ Internal and external communication

The speech act theory provides the means to examine the utterances beyond their surface meaning and understand their functions [16]. McCarthy [17] explained speech acts as "what a piece of language is doing or how the listener or reader is supposed to react". It relates to language function and the relationship between function and grammar. The language functions and the 
speech acts used in the organization's emails were examined in order to understand the features of email communication in the organization under investigation. The emails were classified into different categorize based on their purpose such as: explaining, requesting, informing, and inquiring. The information is summarized in Table 2. The emails were also classified according to the speech act categories of directive, commissive, representative, expressive, and declarative.

From Table 2 it can be seen that most emails were written to inform $26.5 \%$. In addition, the second and third frequent functions of the written emails were to request and explain.

In order to conduct the function analysis, all the 112 emails were analysed using the $\mathrm{N}$ vivo 8 software. The data were analysed according to four major classifications including: Conversational Strategies, Mood, Speech Acts and the Language of Email. Since each of these major classifications included some subcategories, they were each assessed and further categorised into subcategories based on the speech act theory.

The findings relating to the function of emails such as to inform, request and explain and the significant number of directives written in emails in the context of workplace communication, were consistent with the findings of other studies such as [9, 18-20]. The findings regarding to the use of directives speech act showed that there was no significant difference to get the work done in most email messages. Such a finding might be so because the format adopted when writing emails in a directive context is generally the same format as that of a memo format used in most organizations.

\section{Results and Discussion}

The speech act category was classified into 5 subcategories of commissives, declaratives, directives, expressives, and representatives. Under the directive speech act, three sub-categories of imbedded imperatives, imperatives and permission directives were recognized in the data. The sub-categorization was done based on the definitions given for speech acts in the literature review.

As it can be seen from Table 2, based on the results derived from the gathered information most of the emails fell under the Directive category of speech acts with a value of almost $73 \%$ which was followed by representative $19 \%$. This was also clearly illustrated in Table 1 where Directive was leading among all the categories considered for the study.

A few sample examples from the data are presented here to give the reader an insight on the qualitative analysis. All email messages in this study were coded accordingly. Each email communication of the study coded as following;

For example: E\#1

- "E"- refer to the Email word

- \# 1- refers to the number of email

\section{Speech act :Commissives}

Commissives are used to show that the speaker commits to some future action, they express what the speaker intends to do such as promises, threats, refusals and pledges. They are used to impose an obligation to the speaker by him [21].

Table 2. Functions of Email Messages.

\begin{tabular}{|c|c|c|}
\hline Functions of Email Messages & Selected Company & $\mathbf{\%}$ \\
\hline Inform & 25 & 26.5 \\
\hline Request & 21 & 22.3 \\
\hline Explain & 18 & 19.1 \\
\hline Call for meeting & 8 & 8.5 \\
\hline Confirm & 9 & 9.5 \\
\hline Acknowledge & 3 & 3.1 \\
\hline Explain-request & 10 & 5.3 \\
\hline Inquire & 10 & 3.1 \\
\hline Disagree & 2 & 2.1 \\
\hline Instruct & 4 & 0 \\
\hline Total & 112 & 100 \\
\hline
\end{tabular}

Table 3. The Breakdown of the Emails based on the Speech Act Categories.

\begin{tabular}{|c|c|}
\hline Speech Act Categories & Percentage \\
\hline Directive & \multirow{2}{*}{$73 \%$} \\
\hline "I need your opinion..." & \multirow{2}{*}{$19 \%$} \\
\hline Representative & \multirow{2}{*}{$5 \%$} \\
\hline "I suspect the patient has..." & \multirow{2}{*}{$3 \%$} \\
\hline "I really appreciate the suggestions..." & \\
\hline Commissive & \\
\hline "I will post the test results when I get..." & \\
\hline
\end{tabular}


Figure 1. Percentage Coverage for Speech Act.

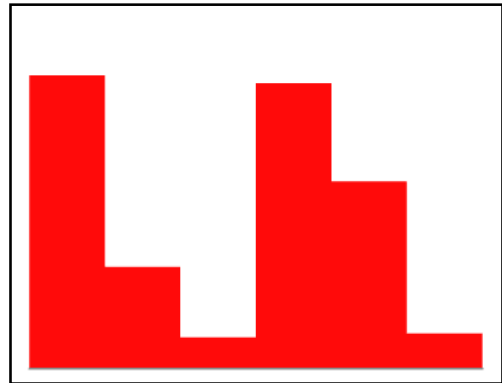

I am in US right now. Sorry for the delay (many stuffs I had to do). You are absolutely right. I will do my best to provide you the new versions of the software.

\section{(E\#1)}

\section{Speech act: Declarative}

In the declarative speech the speaker declares a new social fact to be in the case, such as in the act of marrying, naming a baby or naming a ship [21].

Thank you for your e-mail, but we did not receive any updated Proforma.

By the way I should also remind a mistake of mine and that's to replace the B212 with the B112.G2.KS.QLS (the model as we ordered before). (E\#17)

\section{Speech act: Directive}

The directive request consisted of emails that asked for action. This was usually carried out by the writer when explaining situations and subsequently asking for action. (Dirven, 2004). Some of the most common occurrences used are mentioned in the example below:

Thank you for your email. We are investigating your email and we will get back to you as soon as possible. This email is auto response email; please do not reply to this email again. (E\#92)

\section{Speech act: Expressive}

The emails in this category expressed gratitude. For example, thanks for payment received, and thanks for previous emails received. It was usually sent to one receiver and in certain situations. A few examples of the email texts under this category are provided below:

dear mr Jafarzadeh

thank you for your message. As I am unable to find the message dated $12 / 08 / 2007$, can you please forward to me to proceed. (E\#14)

\section{Speech act: Representative}

The representative included verifying information in the earlier email, to explain why an action was not taken earlier, and to make alteration to an earlier call-for-meeting notice. These emails were circulated to people of the same level of authority in the same department as well as to people in different department. Also it was used in emails explaining the procedures.

With reference to the previous calls I should declare that our company is an active community in the field of advertisement, advertising gifts, design and interior ration. (E\#99)

The most direct form of communication was exemplified in the directives given as direct and indirect requests. In the direct form, the requests functioning as directives, took the form of 'please + imperative', the use of performative in the declarative form or the 'wh-imperative' acted as declarative statement (in which case this constituted the indirect request) examples provided previously. Within the data there were instances in the email exchanges where politeness markers were used to soften the illocutionary force of the utterance when directives are necessary. This was achieved with the use of model verbs 'could + subject + please' construction. The adoption of both the direct and indirect strategies of getting things done in a selected organisation was in agreement with Fairclough [22] statement that speech acts can be given a relatively direct or indirect expression. He explained that indirect speech act such as 'hinting' commands implied a categorical power relationship.

According to the speech act analysis the data shows that email was used mostly to achieve the directive functions of speech acts similarly to when a speaker (sender) makes a request to a hearer (receiver) to be complied with. These happened because there was unequal power relation between the sender and receiver and this was explained by the different role-relationship found in the organisation. The speech acts of directive intent were used as a means to exercise power and to get things done which was an example of an overt exercise of power. The study found that within the selected organisation, the directives were issued either by superiors to subordinates or by peers to peers having functional authority over another and there was a substantial number of emails written by people at the same level of authority but from different departments or divisions.

Email is considered as an effective means of communication in any organisation and the features of email communication in the selected Iranian Company were investigated in this study. The results showed that the email exchanges in this organisation are business emails and they follow the same categories of speech acts as any other feature of communication, but their emphasis is on the directive functions of the communication. In this organisation email is treated more like written rather than spoken discourse and the employees tend to represent a high degree of politeness which makes the emails look more official and formal. 


\section{Conclusion}

The analysis of data showed that using email as a medium of business communication plays an important role in the selected organization in Iran. All the employees find the use of emails challenging but difficult due to the lack of skills in typing, computer, or English language however the data showed that they agree that improving these skills can help them to have a better and more effective email communication. They all tend to be very polite and consider email more like a written document rather than speech. The data indicated that they use polite openings and closings to appear polite and official. From the study it can be concluded that based on the results derived from the gathered information most of the emails fell under the Directive category of speech acts with a value of almost $73 \%$ which was followed by representative $19 \%$. So, it show that most of the emails transmitted ad Directive for of the Speech Act.

Since all the employees of the selected Company are Iranians, their email exchanges may be considered as a representative for the Iranian email discourse. But it should be mentioned that this study was too limited to be able to be over generalized to all the Iranian email discourse. All the emails included a header showing the identity of the sender and the receiver and the subject of the mail. The opening was always respectful and polite. But the phrases were cliché and almost all begin with "dear ..." this can be an indication of a weak English language skill. As the employees have mentioned in the questionnaire, most of them believe that improving their English language skills can help in using emails in a more productive way. The body of all the emails represented the business emails. All the emails were related to the business and work issues. The language used was straight forward and simple. Some traces of grammatical errors were visible. All the emails were ended by a closing and the closing phrases were the same for almost all the emails.

Emails were used to send communications relating to activities including passing and asking information, giving directions, working on papers, providing comments, making requests, soliciting opinions, organizing meetings, and responding to earlier messages. However, they generally stated that they will not use emails to resolve internal disagreements or to share private information, preferring instead to write a letter in these instances. For the workers, all email interactions within the organization were business-related.

\section{Implication and Recommendation}

The goal of this study was to characterize institutional type in the professional context by looking at the electronic mail communication of a specific Iranian organization. As a result, the study looked into discourse analysis of email communication in order to classify linguistic characteristics and rhetorical techniques in email as an institutional type. The categorization might be used as a checklist for members of organizations to follow when using rhetorical tactics and linguistics elements in email. The findings on the categorization of email conversation are another implica- tion of this study.

The findings would be able to give insight into the discourse and rhetorical strategies employed by an organization in its everyday operations to fulfill its unique communicative demands. In addition, the findings would be able to differentiate aspects or characteristics that appear to impact the design of email messages in the workplace.

This study may be repeated in other types of organisations such as educational or official settings. Other languages may be selected as the language of email and the native language of the senders and recipients and the differences that may occur can be investigated. The study may be conducted in different organisations to compare the email discourse, functions and styles in different organisations.

\section{References}

[1]. Tassabehji R, Vakola M. Business email: The killer impact. Communications of the ACM. 2005 Nov 1;48(11):64-70.

[2]. Bafoutsou G, Mentzas G. A comparative analysis of web-based collaborative systems. In12th International Workshop on Database and Expert Systems Applications 2001 Sep (3): 496-500).

[3]. Kruger J, Epley N, Parker J, Ng ZW. Egocentrism over e-mail: Can we communicate as well as we think?. Journal of personality and social psychology. 2005 Dec;89(6): 925.

[4]. Adam R. Is e-mail addictive? Alib Proceedings, 2002; 54(2): 85-94.

[5]. Naughton J. A brief history of the future: The origins of the Internet. 1990: London: Weidenfeld and Nicolson.

[6]. Crystal D. Language and the Internet. New York: Cambridge University Press. 2001.

[7]. Rice RP. The rhetoric of e-mail: An analysis of style. In 1995 IEEE International Professional Communication Conference. IPCC 95 Proceedings. Smooth Sailing to the Future 1995 Sep 27: 110-115.

[8]. Madanchian MI, Taherdoost HA. Structure of Email Discourse in a Selected Iranian Organization. Recent Advances in Telecommunications, Informatics and Educational Technologies. 2014:215-22.

[9]. H, H. Patterns of Electronic Email Discourse in tow Malaysian Organisation. 2003, Universiti Putra Malaysia : Unpublished doctorial Dissertation.

[10]. Searle JR, Speech Acts. 1969: Cambridge: Cambridge University Press.

[11]. Ågerfalk PJ. Investigating actability dimensions: a language/action perspective on criteria for information systems evaluation. Interacting with Computers. 2004 Oct;16(5):957-88.

[12]. Austin JL. How to Do Things with Words. 1962: Oxford: Clarendon Press. Ballard.

[13]. Coulthard M. An Introduction to Discourse Analysis. 1977: London: Longman.

[14]. Ervin-Tripp S. Is Sybil there? The structure of some American English directives. Language in society. $1976 \mathrm{Apr}$; $(1): 25-66$

[15]. Hatch E. Discourse and language education. Cambridge University Press; 1992 Jan 31.

[16]. Cook G. Discourse. 1989: Oxford : Oxford University Press.

[17]. McCarthy M. Discourse analysis for language teachers. Cambridge University Press; 1991 May 2

[18]. Rice RP. An analysis of stylistic variables in electronic mail. Journal of Business and Technical Communication. 1997 Jan;11(1):5-23.

[19]. Gains J. Electronic mail-A new style of communication or just a new medium?: An investigation into the text features of e-mail. English for specific purposes. 1999 Mar 15;18(1):81-101.

[20]. Language and power: a critical analysis of email text in professional communication. 1997.

[21]. Dirven R. Major strands in Cognitive Linguistics. 2004: Essen: LAUD, Series.

[22]. Fairclough N. Language and Power. 1989, London, UK: Longman. 